\title{
Normative data of neuropsychological tests of attention and executive functions in Ecuadorian adult population
}

\begin{abstract}
Alberto Rodríguez-Lorenzana ${ }^{\mathrm{a}}$, Daniela Ramos-Usuga ${ }^{\mathrm{b}, \mathrm{c}}$, Lila Adana Díaz ${ }^{\mathrm{a}}$, Guido Mascialino ${ }^{\mathrm{a}}$, Tarquino Yacelga Ponce ${ }^{\mathrm{a}}$, Diego Rivera ${ }^{\mathrm{d}}$, and Juan Carlos Arango Lasprilla $a^{\text {be,f* }}$

${ }^{a}$ Escuela de Psicología, Universidad de Las Américas, Quito, Ecuador; ${ }^{b}$ Biocruces Bizkaia Health Research Institute, Barakaldo, Spain; ${ }^{c}$ Biomedical Research Doctorate Program, University of the Basque Country (UPV/EHU), Leioa, Spain; ${ }^{d}$ Departamento de Ciencias de la Salud, Universidad Pública de Navarra, Navarra, España; eIKERBASQUE. Basque Foundation for Science, Bilbao, Spain; ${ }^{f}$ Department of Cell Biology and Histology, University of the Basque Country (UPV/EHU), Leioa, Spain
\end{abstract}

*Corresponding author:

Grupo de Psicología y Salud

Biocruces Bizkaia Health Research Institute.

IKERBASQUE. Basque Foundation for Science.

Plaza de Cruces s/n. 48903

Barakaldo, Bizkaia, Spain.

Phone: (34) 946006000 (Ext. 7963)

E-mail: jcalasprilla@gmail.com

This is an accepted manuscript of an article published by Taylor \& Francis in Aging, Neuropsychology and Cognition on $15 \mathrm{Jul}$ 2020, available online: https://doi.org/10.1080/13825585.2020.1790493 


\section{Normative data of neuropsychological tests of attention and executive functions in Ecuadorian adult population}

Objective: The purpose of this study was to generate normative data for five tests of attention and executive functions (M-WCST, Stroop test, TMT, BTA, and SDMT), in a group of 322 Ecuadorian adults from Quito between the ages of 18 and 85. Method: Multiple linear regression analyses taking into account age, education, and gender were used to generate the normative data. Results: Age and education were significantly related to test performance such that scores decreased with age and improved as a function of education. An online calculator is provided to generate normative test scores. Conclusions: This is the first study that presents normative data for tests of executive functions and attention in an Ecuadorian adult population. This data will improve the clinical practice of neuropsychology and help to develop the field in the country.

Keywords: Regression models; normative data; attention; executive functions; Spanish-speaking population; Ecuador; adult. 


\section{Introduction}

Executive functions are a set of psychological processes and behaviors responsible for goal-oriented, self-directed, and self-regulated socially appropriate conduct (Lezak, 2012; Strauss, Sherman, \& Spreen, 2006; Stuss, 2011). Although numerous and diverse conceptualizations of executive functions have been proposed, all recognize their importance for adaptive behavior, particularly in novel situations with complex task demands (Jurado \& Rosselli, 2007). As such, they hold a supervisory role over other cognitive abilities and govern their effective functioning towards goal attainment (Baddeley, 1996; Shallice, Burgess, \& Robertson, 1996). While some researchers disagree about the unified vs. possibly discrete nature of this group of abilities (Stuss, 2011), most definitions posit that executive functions include subcomponents. Lezak (2012), for example, identifies four components: 1) volition, 2) planning/decision making, 3) goal-oriented behavior, and 4) effective execution. Other conceptualizations focus on the frankly cognitive rather than behavioral dimensions of executive control, such as attentional processes (Baddeley, 1998) and/or inhibitory control (Barkley, 1997). Yet another theory emphasizes the process of problem-solving and strategy generation in goal attainment (Zelazo, Carter, Reznick, \& Frye, 1997). In spite of this theoretical heterogeneity, no author denies that executive functions are necessary for independent functioning and adaptive behavior throughout the lifespan (Jurado \& Rosselli, 2007).

In a similar vein, adequate attention functioning is a prerequisite for effective performance in all other cognitive domains. Broadly, it can be defined as the capacity for focused and sustained behavior while filtering irrelevant stimuli (Lezak, 2012; Strauss et al., 2006). As with executive functions, there are various theories of attention, all of which have in common the division of this cognitive process into several 
subprocesses. For example, Sohlberg \& Mateer's model (2002) proposes five types of attention, which are organized hierarchically: focused, sustained, selective, alternating, and divided attention (Sohlberg \& Mateer, 2002). On the other hand, Posner's model (Petersen \& Posner, 2012) holds that attention is a system made up of three networks each responsible for different attentional functions and associated with specific brain regions: 1) Alerting network, responsible for reaching and/or maintaining the alerting state (sustained attention), 2) Orienting network, which orients and selects the source of stimulation, and (3) Executive network, which allows regulating thoughts, emotions, and actions. Functions associated with the Executive network, as the name indicates, overlap to some extent with executive functions, particularly with regard to mental or attentional flexibility, inhibitory control, and conflict monitoring/resolution, and as a result, they are often considered joint and essential aspects of a neuropsychological evaluation (Baddeley, 1996; Blair \& Ursache, 2011; Lezak, 2012; Welch, 2001).

The available literature on the effects of age on attention is inconsistent. While some studies find that attention remains intact during normal aging (Berardi, Parasuraman, Haxby, 2001; Bunce \& Sisa, 2002), others show that this cognitive ability declines as age progresses (Deaton \& Parasuraman, 1993; Godefroy, Roussel, Despretz, Quaglino, \& Boucart, 2010; Mahoney, Verghese, Goldin, Lipton, \& Holtzer, 2010; Mani, Bedwell, Miller, 2005). Mahoney et al. (2010) used The Attention Network Test (ANT) to assess alerting, orienting, and executive attention in older adults, and found that chronological age did not influence alerting or orienting, but did affect executive attention, so that the ability to resolve conflicts decreases significantly with age. These results are consistent with previous studies that found a similar performance among young and old people in tests that measure alerting (Fenandez-Duque \& Black, 2006; Greenwood, Parasuraman, \& Haxby, 1993; Tales, Muir, Bayer, Jones, \& Snowden, 
2002; Parasuraman, Nestor, Greenwood, 1989) and orienting networks (Danckert, Maruff, Crowe, \& Currie, 1998; Folk \& Hoyer, 1992; Hartley and Kieley, 1995). Some authors have suggested that these results can be explained through the mindlessness theory of vigilance (Helton \& Warm, 2008), according to which problems on vigilance tasks are due more to motivational issues or boredom than to alterations in the attentional processes. Thus, since older people tend to be more intrinsically motivated than younger people, they are less likely to experience momentary disconnections, allowing them to perform similarly (Manly et al., 1999, 2004; O’Connell et al., 2008; Robertson et al., 1997).

Furthermore, the findings of Mahoney et al. (2010) about the Executive attention network also agree with other studies in which a considerable decline in this network (Zeef, Sonke, Kok, Buiten, \& Kenemans,1996) and executive functions is observed with increasing age, attributed to the deterioration of the function of the prefrontal cortex (Sorond, Schnyer, Serrador, Milberg, \& Lipsitz , 2008; Raz et al., 1997), due to a decrease in cerebral blood flow and oxygenated hemoglobin (Hamasaki et al., 2018; Raz \& Rodrigue, 2006).

When executive functions are compromised, changes in personality, cognition, and behavior often follow (Burgess \& Robertson, 2002; Godefroy et al., 2010). Likewise, attention deficits often have a wide-ranging impact across an individual's cognitive and emotional functioning. Deficits in both and/or either domain are found in a number of pathologies including but not limited to traumatic brain injury (Cicerone $\&$ Giacino, 1992; McDonald, Flashman, \& Saykin, 2002; Shah et al., 2017; Tramontana, Cowan, Zald, Prokop, \& Guillamondegui, 2014), stroke (Olgiati, Russell, Soto, \& Malhotra, 2016; Pohjasvaara et al., 2002; Vataja et al., 2003), frontotemporal dementia (Bozeat, Gregory, Lambon Ralph, \& Hodges, 2000; Huey et al., 2010), Alzheimer's 
disease (Binetti et al., 1996; Swanberg, Tractenberg, Mohs, Thal, \& Cummings, 2004), Huntington's disease (Lawrence et al., 1996; Peinemann et al., 2005), Parkinson's disease (Papagno \& Trojano, 2018; Zgaljardic et al., 2006), attention-deficit hyperactivity disorder (Kingdon, Cardoso, \& McGrath, 2016; Margari et al., 2016), and schizophrenia (Dirnberger, Fuller, Frith, \& Jahanshahi, 2014; Gavilán \& García-Albea, 2015) among others.

The evaluation of attention and executive dysfunction is a complex matter, largely due to the multifactorial nature of the domains, which in turn underscores the importance of appropriate test choice (Chan, Shum, Toulopoulou, \& Chen, 2008; Lezak, 2012; Suchy, Ziemnik, \& Niermeyer, 2017). There is a multitude of neuropsychological measures of attention and executive functions available to the clinician, although some in particular have become staples of a neuropsychological battery (Chan et al., 2008; Mitrushina, 2005; Strauss et al., 2006). Widely used instruments include the Modified Wisconsin Card Sorting Test (M-WCST; (Nelson, 1976; Schretlen, 2010), the Stroop Color and Word Test (SCWT; Golden \& Freshwater, 2002; Stroop, 1935), the Brief Test of Attention (BTA; Schretlen, 1997), the Trail Making Test (TMT; Army Individual Test Battery, 1944), and the Symbol Digit Modalities Test (SDMT; Smith, 2002).

Several studies have been conducted in order to generate normative data for the aforementioned tests in Spanish-speaking countries including Spain (Del Pino et al., 2016; Peña-Casanova et al., 2009; 2012), Argentina, Bolivia, Chile, Cuba, El Salvador, Guatemala, Honduras, Mexico, Paraguay, Peru, and Puerto Rico (Arango-Lasprilla et al., 2015a; 2015b; 2015c; Rivera et al., 2015a; 2015b). In all the studies, the following variables were considered: age, educational level, and sex. The results from all studies reflected a clear influence of schooling on performance on all tests, with a higher level 
of education correlated with better scores.

Similarly, age had a significant impact on performance on tests of executive functions and attention, although in this case advancing age was associated with decreased performance. Thus, despite the variability of results found in the literature regarding the effect of age on attention, studies that provide normative data for tests of attention and executive functions in Spanish-speaking populations show a clear decrease in these cognitive abilities as age advances. Results for the effects of sex were mixed. Arango-Lasprilla et al. (2015b) showed significant differences for the M-WCST in the number of correct categories by sex of the participants in some countries (Argentina, Chile, El Salvador, Guatemala, Honduras, Mexico, and Paraguay), while Del Pino et al. (2016) did not. Concerning the Stroop Color and Word Test, Rivera et al. (2015b) found differences with respect to sex in some countries, although these data were not included in the derived norms since the effect for all countries was less than 0.30. Differences in performance on the BTA, TMT, and SDMT by sex were only seen in Honduras out of nine other countries examined (Arango-Lasprilla et al., 2015a; 2015c; Rivera et al., 2015a).

The present study is the first effort to provide country-specific normative data for adults in Ecuador for the aforementioned tests of attention and executive functions, all of which have shown adequate psychometric qualities and are widely used by professionals in the country to evaluate these domains. Currently, neuropsychology in Ecuador is in a state of growth (Ramos-Galarza, 2017), and the systematic generation of national norms, adjusted to the characteristics of the population, should contribute to this effort by improving the adequate and rigorous use of these neuropsychological tests potentially improving diagnostic accuracy and concomitant treatment recommendations. Consequently, the aim of this study is to derive normative data for Ecuadorian 
population ages 18 to 85 years stratified by age, gender, and level of education, which have shown an effect on performance in the studies.

\section{Method}

\section{Participants}

The original sample of this study consisted of 332 healthy individuals who were recruited from Quito, Ecuador. A total of $n=10$ participants were excluded from the analyses because of incomplete information, yielding a final sample of 322 participants. The sample was collected considering the educational level (low, medium, and high), sex, and age distribution for Ecuador. An empirical quota sampling was used, and the accuracy of the final sample was established using classical estimation assuming infinite (very large) population sizes (Arrufat, Guàdia-Olmos, \& Blanxart, 1999), with a statistical precision of 0.06 ( $94 \%$ accuracy) under the situation of maximum uncertainty $(\pi=1-\pi=0.5)$ and a confidence interval of 95\%. Participants' ages ranged from 18 to 85 years $(\mathrm{M}=41.3, \mathrm{SD}=18.2)$. Education ranged from 2 to 25 years $(\mathrm{M}=13.2, \mathrm{SD}=$ 4.6). The majorities were women (54.04\%), and the sample was primarily urban $82.8 \%$. The sociodemographic characteristics of the participants (age, education, and sex) can be found in Table 1.

Insert Table 1

The inclusion/exclusion criteria was the following: (a) age between 18 to 85 years, (b) born and currently live in Ecuador, (c) spoke Spanish as their native language, (d) at least 1 year of formal education completed, (e) be literate, (f) scored $\geq 23$ on the Mini-Mental State Examination (MMSE; Folstein et al., 1975), (g) scored $\leq 4$ on the 
Patient Health Questionnaire-9 (PHQ-9, Kroenke et al., 2001), (h) scored $\geq 90$ on the Barthel Index (Mahoney \& Barthel, 1965), (i) not to have history of neurological or psychiatric conditions, systemic disease (diabetes mellitus, hypothyroidism, B12 deficiency, lupus, chronic cardiac insufficiency, and sleep apnea), and learning problems or developmental disabilities, (j) not to have severe visual and/or hearing deficit, and (k) not to use/abuse of an illicit substance and/or medications that may impact cognitive functioning (antidepressant, anxiolytic, anticonvulsant, and antipsychotic drugs).

\section{Instruments and Measures}

A self-report questionnaire was developed by the researchers to collect information about the participants' health status and clinical history. This information was used to identify participants who meet the exclusion criteria proposed for the present study. During the interview, the following information was obtained: demographic data, motor, language, visual, and/or auditory problems; assistance received by different professionals (e.g. neurologist, psychiatrist, medical rehabilitation professional, occupational therapist, speech therapist, psychologist), the existence of psychological disorders, the use/abuse of illicit substance, and pharmacological treatment.

Modified Wisconsin Card Sorting Test (M-WCST; Nelson, 1976). M-WCST is a test of executive functions in which the participant must sort cards, containing geometrical figures varying in color and number, according to categorical rules that are not made explicit. The participant must learn the rule from feedback provided to him or her about the correctness of the sorting response. The test allows for the calculation of the number of categories, perseverative errors, and total errors (Schretlen, 2010).

The Stroop Color and Word Test (Golden, 1994). It consists of three pages: a) the sheet "Stroop Word" consists of the words "Red," "Green," and "Blue" in black ink, 
and the score is the number of words read correctly, b) the sheet "Stroop Color" contains groups of four X's ("XXXX") printed in blue, green, and red, and the score is the number of colors properly named, and c) the last sheet "Stroop Color-word" consists of the three words of the first page but printed in the colors of the second, with words being incongruent with the color of the ink. The task is to name the ink color, inhibiting the reading of the word, and the score is the number of correctly named elements. The participant has 45 seconds to read aloud, as quickly as possible, the columns from left to right. Finally, the Interference Index is calculated with the formula: $\mathrm{WC}-[(\mathrm{W} \times \mathrm{C}) /(\mathrm{W}+$ C)], and indicates the degree to which the person has control over interference.

Trail Making Test (TMT; Reitan, 1958). It consists of two parts: TMT-A and B. In the TMT-A the individual must draw a line to connect 25 numbers in ascending order, which are circled and randomly distributed on a sheet of paper. The task requirements are similar for the TMT-B, except that the person alternates between numbers and letters (1-A, 2-B, 3-C, etc.). While part A requires sustained attention, part B involves more complex cognitive skills such as mental flexibility and ability to maintain set. The score is the time that an individual takes to finish the task in each test, with a maximum of 100 and 300 seconds for TMT-A and TMT-B, respectively.

Symbol Digit Modalities Test (SDMT; Smith, 1982) It consists of a key with two rows, with nine stimulus symbols in the upper row and matched numbers (1-9) in the row below it. The task sequence consists of a series of symbols, each with a blank space underneath, in which the subject is asked to consecutively fill with the corresponding numbers as fast as possible in 90 seconds after completing a 10-item practice trial. The score of the test is the number of correct substitutions completed within the time limit, with a maximum score of 110 . 
The Brief Test of Attention (BTA; Schretlen, Bobholz \& Brandt, 1996). The BTA is a measure of divided attention which requires listening to alpha-numeric strings and tallying up the total numbers presented (BTA-N). On a second trial, the participant must instead tally up the letters (BTA-L). The scores of the test are the number of correct items in the BTA-N, BTA-L, and the sum of both scores. Because of its exclusive aural modality, it avoids visual acuity and motor confounds. Test reliability (a $=.80)$ and test-retest stability (.70; Schretlen, 1997) are good to high, and it presents with convergent validity through correlation with the Stroop and Trail Making Test (Schretlen, 1997).

\section{Procedure}

The present study was conducted as part of a larger study to generate statistical normative data for a series of neuropsychological measures in Spanish speaking populations (Guàrdia-Olmos, Peró-Cebollero, Rivera, \& Arango-Lasprilla, 2015; Rivera \& Arango-Lasprilla, 2017). The ethics committee that approved the study was "Comité de ética de investigación en seres humanos (CEISH-USFQ)". Participants were volunteers from the community recruited through announcements distributed in local businesses, community centers, and through the university staff. All the persons that showed interest in participating were contacted by a member of the research team, who explained the nature of the study and answered any questions that the person might have. People that agreed to participate signed the informed consent, according to the Helsinki Declaration. Then their sociodemographic data were collected followed by the application of a screening test to verify inclusion and exclusion criteria. The neuropsychological tests were applied to the participants that satisfied the criteria. The assessment lasted between 80 and 120 minutes. The research was conducted in the facilities of the Universidad de las Americas. No compensation was provided for 
participation in the study. Data collection started in May 2017 and ended in March 2019.

\section{Statistical Analyses}

Exploratory data analysis

Pearson correlations between the M-WCST (Categories, Perseverative errors, and Total errors), Stroop test (Word, Color, Color-word, and Interference), TMT (A and B), SDMT, and BTA scores and the sociodemographic (age, education, and sex) variables were computed (see Table 2).

Insert Table 2

\section{Demographic effects and generation of normative data}

M-WCST, Stroop test, TMT, SDMT, and BTA scores were computed separately. The means of multiple linear regression analyses were used to evaluate the effects of demographic variables on each score. Age, age ${ }^{2}$, education, education ${ }^{2}$, sex, and all twoway interactions between these variables were included in the full regression models. Squared terms of age and education were added in the full model to assess the curvilinear effect, centralizing them previously to avoid multicollinearity (age in years $x$ age in the sample; education in years - $x$ education in the sample) (Aiken $\&$ West, 1991). Sex was dummy coded as man $=1$ and woman $=0$. The model assumes that the residuals are normally distributed with mean 0 and variance $\sigma_{\varepsilon}^{2}$, i.e., $\varepsilon_{i} \sim N\left(0, \sigma_{\varepsilon}^{2}\right)$. Independent variables that were not statistically significant (Bonferronicorrected $\alpha$-level of .01) in the multiple regression models were removed, except those predictors also included in a higher-order term (Aiken \& West, 1991). After removing 
each variable, the model was fitted again. Then, the following assumptions were evaluated for each model: multicollinearity (Variance Inflation Factor $[\mathrm{VIF}] \leq 10$ ), homoscedasticity (participants were grouped into quartiles of the predicted scores and the Levene's test was applied on the residuals), normality of the standardized residuals (Kolmogorov-Smirnov test), and the existence of influential values assess [calculation of the maximum Cook's distance, and subsequently related to an $F(p, n-p)$ distribution] (Kutner et al., 2005).

Finally, to generate normative data adjusted by sociodemographic variables a four-step procedure was performed for each score, separately (Rivera et al., 2019; Van Breukelen \& Vlaeyen, 2005; Van der Elst et al., 2006a; Van der Elst et al., 2006b): a) the expected test score $\left(\hat{Y}_{i}\right)$ is computed using fixed-effect parameter from the final regression model: $\hat{Y}_{i}=B_{0}+B_{1} X_{1 i}+B_{2} X_{2 i}+\cdots+B_{K} X_{K i}$, b) the residual value $e_{i}=$ $Y_{i}-Y_{i}$ is calculated, c) the residuals are standardized using the residual standard deviation $\left(S D_{e}\right)$ value provided by the regression model (see Table 3): $z_{i}=e_{i} / S D_{e}$, and d) the exact percentile corresponding to the $z$-score is obtained using the standard normal cumulative distribution function (if normality assumption is met), or the empirical cumulative distribution function of the standardized residuals (if normality assumption is not met).

Insert Table 3

Adjusted $R^{2}$ values are provided for all final models. SPSS Version 23 (IBM Corp., Armonk, NY). 
The four-step normative procedure explained above allows to determine an exact zscore and percentile for each of the raw scores of attention and executive functions' tests (M- WCST, Stroop test, TMT, SDMT, and BTA). However, due to the complexity and the number of required computations by hand, it is easy to make mistakes. To enhance user-friendliness, the authors created a calculator in Microsoft Excel using these steps in which the clinician must include the following information: raw score (MWCST (Categories, Perseverative errors, and Total errors), Stroop test (Word, Color, Color-word, and Interference), TMT (A and B), SDMT, and BTA), age, education, and sex to calculate the $\mathrm{z}$ score and percentile automatically. This tool is freely available for all users and may be downloaded at www.masked.com.

\section{Results}

\section{Exploratory data analysis}

M-WCST Categories, Stroop test (Word, Color, Word- color, and Interference), SDMT, and BTA scores correlated significantly negative with age (r's $\leq-0.212 ; p$ 's $<0.001)$, and significantly positive with education (r's $\geq 0.339 ; p$ 's $<0.001$ ). Otherwise, MWCST (Perseverative errors and Total errors), and TMT (A and B) scores correlated significantly positive with age (r's $\geq 0.432 ; p$ 's $<0.001)$ and significantly negative with education (r's $\leq-0.216 ; p$ 's $<0.001)$. Finally, the variable sex correlated significantly positive with Stroop Word and Stroop Color scores (r's $\geq 0.118 ; p$ 's $<0.05$ ), and significantly negative (r's $\leq-.087 ; p$ 's $<0.05)$ with TMT-A.

\section{Model assumptions}

The assumptions of multiple linear regression analysis were largely met for all final models. There was no multicollinearity (VIF values $\leq 1.997)$ or influential cases [maximum Cook's distance $=0.574$; relating this value to an $F_{(7,315)}$ distribution yields a 
percentile value of 22 , which is below the threshold $(\mathrm{PE}=50)$ that is indicative for the presence of influential cases]. The Levene test suggested that there was heteroscedasticity in all models except in the Stroop test (Word, Color, Color-word, and Interference) and SDMT scores. Standardized residuals of the models were normally distributed (Kolmogorov-Smirnov test) except for M-WCST Categories, Perseverative errors, and TMT-B.

\section{$M-W C S T$}

The final multiple linear regression models for M-WCST Categories, Perseverative errors, and Total errors scores were significant (see Table 4). M-WCST Categories score was negatively influenced by age and increased linearly as a function of education. The amount of variance (adjusted for the number of predictors in the final model; adjusted R2) explained by these predictors was 28\%. M-WCST Perseverative errors score increased curvilinearly as a function of age and decreased curvilinearly as a function of education. Quadratic age by quadratic education interactions also affected the score, so that up to 30 years, people with more years of education have fewer perseverative errors than those with less education. From 35 to 60 years, the performance of people with 5,10 , and 15 years of education is similar, while those with 20 or more years of education maintain a better performance than others up to 50 years, showing an increase of perseverative errors as the age increases until reaching the worst performance in comparison with the people with less education (see Figure 1). The amount of variance explained by these predictors was 37\%. Finally, M-WCST Total errors score was positively influenced by the quadratic age and decreased linearly as a function of education. The interaction between age and education also affected the score, so that up to age 65 , participants with more years of education have fewer perseverative errors than those with fewer years of education. From this age on, the 
performance is invested in such a way that the higher the education, the more total errors the participants have. The sex variable was not significant. The amount of variance explained by these predictors was $27 \%$.

Insert Figure $1 \&$ Table 4

\section{Stroop Color and Word Test}

The final multiple linear regression models for Stroop Word, Color, Color-word, and Interference scores were significant (see Table 5). Stroop Word, Color, and Color-word scores were negatively influenced linearly by age and increased linearly as a function of education. Stroop Interference score was negatively influenced by age, which means that the older age the more interference. The amount of variance explained by these predictors for Stroop Word, Color, Color-word, and Interference scores were 28\%, 29\%, $38 \%$, and $7 \%$, respectively.

Insert Table 5

$T M T$

The final multiple linear regression models for TMT-A and TMT-B scores were significant (see Table 6). TMT-A score was positively influenced by age and decreased linearly as a function of education so that the time needed to complete the test increases as the age advances and the fewer years of education the person has. TMT-B score was positively influenced by quadratic age and decreased linearly as a function of education, showing a subtle increase in time until 40 years of age and a steeper increase of 40 to 80 years, with people with more years of education performing better than people with 
fewer years of education. The amount of variance explained by these predictors for

TMT-A and TMT-B scores were $28 \%$ and $43 \%$, respectively.

Insert Table 6

$S D M T$

The final multiple linear regression model for SDMT score was significant (see Table

7). The SDMT score was negatively influenced by age and increased linearly as a

function of education, so the performance decreases as the age advances, with people with more years of education having better performance than those with less years of education (see Figure 2). The amount of variance explained by these predictors was $54 \%$.

Insert Figure $2 \&$ Table 7

$B T A$

The final multiple linear regression models for BTA score were significant (see Table

8). The BTA score was affected by a quadratic age effect and increased linearly as a function of education, showing a curvilinear pattern of the score according to age, with people with more years of education having better performance than those with fewer years of education. The amount of variance explained by these predictors was $19 \%$. 


\section{Discussion}

The aim of this study was to generate normative data for five tests of attention and executive functions (M-WCST, Stroop test, TMT, BTA, and SDMT) for an Ecuadorian population between 18 and 85 years. The effect of variables such as age, sex, and years of education on performance in each of the tests was explored.

For the WCST, the model predictors explained between 27 and $37 \%$ of the variance of the variables. Both age and education predicted the performance of the participants in subtests of the M-WCST. Age showed a negative relationship with the number of categories completed while education behaved in the opposite direction. This trend is reversed for total and perseverative errors, although relationships were curvilinear. Additionally, an interaction between quadratic age and quadratic education was noted in which education was associated with improved performance in those below 30 years of age and worse performance in those over 50. Consistent with current results, past studies have found similar associations with age and education (ArangoLasprilla et al., 2015a; 2015b; 2015c; Lineweaver et al., 1999). Finally, the sex variable showed no influence on any of the models. Arango-Lasprilla et al. (2015a) found the sex effects of this test for several Latin American countries. Quadratic effects observed in this study are a new finding that, to the best of the author's knowledge, has not been observed before in norming studies with a Latin American population.

The results obtained for the Stroop test showed a similar trend to that found in the M-WCST, that is, performance worsened with age and improved with education. The only exception is the interference score, in which education did not prove to be a predictive variable. The models explained 7 to $38 \%$ of the variance. Results are consistent with prior studies that found age and education effects on all subtests (Mitrushina, Boone, Razani, \& D'Elia, 2005; Rivera et al., 2015b). 
In the case of the TMT, a negative relationship with education could be seen, that is, greater education was associated with lower test times. Age demonstrated an inverse relationship for both the TMT-A and TMT-B. For this test, the models explained $28 \%$ of the variance for the TMT-A and $43 \%$ for the TMT-B. Consistent with findings on this study, prior work also found an association with age (Strauss et al., 2006) and education (Arango-Lasprilla et al., 2015a).

In the SDMT the same trend observed in previous tests was again appreciated: age was linked to worse performance while education predicted better results. The model for this test explained $54 \%$ of the variance. Past research found results to be related to IQ and education (Richardson \& Marottoli, 1996; Uchiyama, Mitrushina, D’Elia, Satz, \& Mathews, 1994), in line with current results. A gender effect was noted only in one study (Jorm, Anstey, Christensen, \& Rodgers, 2004), which did not appear in this case. On a Latin American sample, similar findings were noted for eleven Latin American countries (Arango-Lasprilla et al., 2015c).

Finally, results for the BTA maintained this trend showing a negative relationship of age with performance and a positive relationship with education. Results are generally consistent with the findings of other studies in Latin American countries (Rivera et al., 2015a).

The results of this study have important clinical and research implications. Because of the lack of normative data in Ecuador, many neuropsychologists use norms from other countries. This is very problematic because some studies have shown significant differences in performance even within specific Spanish-speaking regions such as South America (Buré-Reyes et al., 2013; Duggan, Awakon, Loaiza, \& GarciaBarrera, 2019). This practice can lead to errors in the interpretation of test results, as can be seen in the following example. A 45-year-old Ecuadorian woman with 10 years of 
education gets a score of 35 on the SDMT. If the clinician uses the normative data from Arango-Lasprilla et al. (2015c) for El Salvador, the raw score will correspond to an 80th percentile, with Arango-Lasprilla et al. (2015c) normative data for Bolivia the percentile drops to 60 , and finally, using the normative data from the present study, the percentile would be 45 .

This example illustrates the impact that the methods to generate the normative data and/or or the characteristics of the population sampled may have on the resulting normative data. For example, there are methodological differences in these studies, including different sampling methods and sample sizes, data analysis methods, and years in which the data was collected. The differences may also be due, in part, to differences in the populations from different countries, which may be influenced by quality of education and/or cultural differences concerning attitudes about testing, for example.

These normative data are valuable in multiple ways. The availability of country-specific norms should improve accuracy in the assessment of the cognitive functioning of the Ecuadorian population, which in turn should improve diagnostic accuracy and treatment planning in neurorehabilitation. Furthermore, the prevalence of neurodegenerative disease and cognitive impairment is high in Ecuador (Del Pozo et al., 2018). The availability of tests normed with healthy people in older age ranges in Ecuador, as provided in the current study, can help to detect cognitive deficits in older individuals with mild cognitive deficits or early stage of dementia. In addition, these normative data offer researchers in Ecuador some reliable measures to use in their studies with participants who may present with attention and executive function deficits.

Finally, it should be noted that compared to previous research that has developed normative data for Spanish-speaking countries, this study has a number of advantages. 
A more complex methodology has been used that allowed determining the quadratic effects of age and education, as well as the interactions between the variables, which enhanced the interpretability of the results. Additionally, the calculator allows to obtain $\mathrm{z}$ scores and percentiles in a fast and exact way, taking into account the particular characteristics of each patient, without having to make calculations by hand or search in a table. This will undoubtedly facilitate the work of clinicians.

\section{Limitations}

Some limitations were found in the present study. First, the data was collected in the Metropolitan District of Quito, which means that the sample included mostly people living in urban areas. Future studies should identify the place of residence of the participants to ensure a correct distribution of the rural and urban population based on the distribution of the country. Second, the study did not identify if the people were bilingual. Although in Ecuador Spanish is the official language, in the population census of $2001,4.6 \%$ of the population aged 15 or over declared to speak an indigenous language (Chisaguano, 2006), which could lead to bias in the tests of language, as some studies have shown that bilingualism could affect cognitive performance. Therefore, it is relevant for future studies to evaluate bilingual populations and verify possible differences in test performance. Finally, our study did not control for quality of education and the type of schools and universities that the participants attended. These variables might influence performance in attention and executive function tests. Our results indicate that education is a relevant variable to predict performance in attention and executive functions tests, and as a result, the quality of education should be controlled in subsequent studies. Finally, this study only presented normative data, nevertheless, clinical validation of these tests is necessary to ensure a more accurate diagnosis related to affectations of executive functions and attention. 


\section{Conclusion}

To the best of the authors' knowledge, this is the first study to develop norms for the Stroop test, TMT (A and B), BTA, SDMT, and M-WCST for an Ecuadorian adult population. Sociodemographic variables were analyzed and found to be related to performance thus allowing to produce corrected norms. Lastly, both predictive equations and user-friendly calculator was provided for the clinician to facilitate interpretation. In provided context-appropriate norms, this study is likely to improve diagnostic accuracy and clinical care for the Ecuadorian population, therefore contributing to the already growing field of neuropsychology in the country.

\section{Acknowledgments}

\section{Disclosure of interest}

The authors report no conflict of interest. 


\section{References}

Aiken, L. S., West, S. G., \& Reno, R. R. (1991). Multiple regression: Testing and interpreting interactions. Sage Publications.

Arango-Lasprilla, J. C., Rivera, D., Aguayo, A., Rodríguez, W., Garza, M. T., Saracho, C. P., ... \& Longoni, M. (2015a). Trail Making Test: normative data for the Latin American Spanish speaking adult population. NeuroRehabilitation, 37(4), 639-661. doi: 10.3233/NRE-151284

Arango-Lasprilla, J. C., Rivera, D., Longoni, M., Saracho, C. P., Garza, M. T., Aliaga, A., ... \& Schebela, S. (2015b). Modified Wisconsin card sorting test (M-WCST): normative data for the Latin American Spanish speaking adult population. NeuroRehabilitation, 37(4), 563-590. doi: 10.3233/NRE-151280

Arango-Lasprilla, J. C., Rivera, D., Rodríguez, G., Garza, M. T., Galarza-del-Angel, J., Rodriguez, W., ... \& Longoni, M. (2015c). Symbol digit modalities test: normative data for the Latin American Spanish speaking adult population.

NeuroRehabilitation, 37(4), 625-638. doi: 10.3233/NRE-151284

Army Individual Test Battery. (1944). Manual of Directions and Scoring. Washington, DC: War Department, Adjutant General's Office.

Arrufat, A. S., Olmos, J. G., \& Blanxart, M. F. (1999). Introducción a la estadística en Psicología (Vol. 27). Edicions Universitat Barcelona.

Baddeley, A. (1996). Exploring the Central Executive. The Quarterly Journal of Experimental Psychology Section A, 49(1), 5-28. doi: 10.1080/713755608

Baddeley, A. D. (1998). The central executive: A concept and some miscoceptions. Journal of the International Neuropsychological Society, 4(5), 523-526. Retrieved from https://www.cambridge.org/core/journals/journal-of-the-internationalneuropsychological-society/article/central-executive-a-concept-and-somemisconceptions/7F8EFC63A28D49B0795E11239CDFB815 
Barkley, R. A. (1997). Behavioral inhibition, sustained attention, and executive functions: Constructing a unifying theory of ADHD. Psychological Bulletin, 121(1), 65-94. doi: $10.1037 / 0033-2909.121 .1 .65$

Berardi, Raja Parasuraman, James V. Haxby, A. (2001). Overall vigilance and sustained attention decrements in healthy aging. Experimental aging research, 27(1), 19-39. doi: $10.1080 / 03610730126014$

Binetti, G., Magni, E., Padovani, A., Cappa, S. F., Bianchetti, A., \& Trabucchi, M. (1996). Executive dysfunction in early Alzheimer's disease. Journal of Neurology, Neurosurgery \& Psychiatry, 60(1), 91-93. doi: 10.1136/jnnp.60.1.91

Blair, C., \& Ursache, A. (2011). A bidirectional model of executive functions and selfregulation. In K. D. Vohs \& R. F. Baumeister (Eds.), Handbook of self-regulation: Research, theory, and applications (p. 300-320). Guilford Press.

Bozeat, S., Gregory, C. A., Lambon Ralph, M. A., \& Hodges, J. R. (2000). Which neuropsychiatric and behavioural features distinguish frontal and temporal variants of frontotemporal dementia from Alzheimer's disease? Journal of Neurology Neurosurgery and Psychiatry, 69(2), 178-186. doi: 10.1136/jnnp.69.2.178

Bunce, D., \& Sisa, L. (2002). Age differences in perceived workload across a short vigil. Ergonomics, 45(13), 949-960. doi: 10.1080/00140130210166483

Buré-Reyes, A., Hidalgo-Ruzzante, N., Vilar-López, R., Gontier, J., Sánchez, L., PérezGarcía, M., \& Puente, A. E. (2013). Neuropsychological test performance of Spanish speakers: Is performance different across different Spanish-speaking subgroups? Journal of Clinical and Experimental Neuropsychology. https://doi.org/10.1080/13803395.2013.778232

Burgess, P. W., \& Robertson, I. H. (2002). Principles of the Rehabilitation of Frontal Lobe Function. In Principles of Frontal Lobe Function (pp. 557-572). doi: 
10.1093/acprof:oso/9780195134971.003.0033

Chan, R. C., Shum, D., Toulopoulou, T., \& Chen, E. Y. (2008). Assessment of executive functions: Review of instruments and identification of critical issues. Archives of Clinical Neuropsychology, 23(2), 201-216. doi: 10.1016/j.acn.2007.08.010

Chisaguano, S. (2006). LA POBLACIÓN INDÍGENA DEL ECUADOR ANÁLISIS DE ESTADÍSTICAS SOCIO-DEMOGRÁFICAS. Quito.

Cicerone, K. D., \& Giacino, J. T. (1992). Remediation of Executive Function Deficits after Traumatic Brain Injury. NeuroRehabilitation, 2(3), 12-22. doi: 10.3233/NRE$1992-2304$

Craig, F., Margari, F., Legrottaglie, A. R., Palumbi, R., De Giambattista, C., \& Margari, L. (2016). A review of executive function deficits in autism spectrum disorder and attention-deficit/hyperactivity disorder. Neuropsychiatric disease and treatment, 12, 1191. doi: 10.2147/NDT.S104620

Danckert, J., Maruff, P., Crowe, S., \& Currie, J. (1998). Inhibitory processes in covert orienting in patients with Alzheimer's disease. Neuropsychology, 12(2), 225. doi: $10.1037 / / 0894-4105.12 .2 .225$

Deaton, J. E., \& Parasuraman, R. (1993). Sensory and cognitive vigilance: Effects of age on performance and subjective workload. Human Performance, 6(1), 71-97. doi: 10.1016/j.acn.2004.12.008

Del Pino, R., Peña, J., Ibarretxe-Bilbao, N., Schretlen, D. J., \& Ojeda, N. (2016). Modified Wisconsin Card Sorting Test: standardization and norms of the test for a population sample in Spain. Revista de Neurologia, 62(5), 193-202.

Del Pozo, P. H. E., Espinosa, P. S., Donadi, E. A., Martinez, E. Z., Salazar-Uribe, J. C., Guerrero, M. A., ... \& Altamirano, W. E. (2018). Cognitive Decline in Adults Aged 65 and Older in Cumbayá, Quito, Ecuador: Prevalence and Risk Factors. 
Cureus, 10(9).

Dirnberger, G., Fuller, R., Frith, C., \& Jahanshahi, M. (2014). Neural correlates of executive dysfunction in schizophrenia: Failure to modulate brain activity with task demands. NeuroReport, 25(16), 1308-1315. doi:

10.1097/WNR.0000000000000264

Duggan, E. C., Awakon, L. M., Loaiza, C. C., \& Garcia-Barrera, M. A. (2019). Contributing Towards a Cultural Neuropsychology Assessment Decision-Making Framework: Comparison of WAIS-IV Norms from Colombia, Chile, Mexico, Spain, United States, and Canada. Archives of Clinical Neuropsychology. doi: https://doi.org/10.1093/arclin/acy074

Fernandez-Duque, D., \& Black, S. E. (2006). Attentional networks in normal aging and Alzheimer's disease. Neuropsychology, 20(2), 133. doi: 10.1037/08944105.20.2.133

Folk, C. L., \& Hoyer, W. J., (1992). Aging and shifts of visual spatial attention. Psychology and Aging, 7, 453-465. doi: 10.1037//0882-7974.7.3.453

Folstein, M. F., Folstein, S. E., \& McHugh, P. R. (1975). "Mini-mental state": a practical method for grading the cognitive state of patients for the clinician. Journal of psychiatric research, 12(3), 189-198. doi: 10.1016/0022-3956(75)90026-6

Gavilán, J. M., \& García-Albea, J. E. (2015). Executive dysfunction in schizophrenia and its association with mentalizing abilities. Revista de Psiquiatría y Salud Mental (English Edition), 8(3), 119-129. doi: 10.1016/j.rpsmen.2015.05.003

Godefroy, O., Azouvi, P., Robert, P., Roussel, M., LeGall, D., \& Meulemans, T. (2010). Dysexecutive syndrome: Diagnostic criteria and validation study. Annals of Neurology, 68(6), 855-864. doi: 10.1002/ana.22117

Godefroy, O., Roussel, M., Despretz, P., Quaglino, V., \& Boucart, M. (2010). Age-related 
slowing: perceptuomotor, decision, or attention decline?. Experimental aging research, 36(2), 169-189. doi: 10.1080/03610731003613615

Golden, C. J. (1994). STROOP: Test de colores y palabras: Manual. TEA ediciones S.A.

Golden, C., \& Freshwater, S. M. (2002). Stroop Color and Word Test. Odessa, FL: Psychological Assessment Resources.

Greenwood, P. M., Parasuraman, R., \& Haxby, J. V. (1993). Changes in visuospatial attention over the adult lifespan. Neuropsychologia, 31(5), 471-485. doi: https://doi.org/10.1016/0028-3932(93)90061-4

Guàrdia-Olmos, J., Peró-Cebollero, M., Rivera, D., \& Arango-Lasprilla, J. C. (2015). Methodology for the development of normative data for ten Spanish-language neuropsychological tests in eleven Latin American countries. NeuroRehabilitation, 37(4), 493-499. doi: 10.3233/NRE-151277

Hamasaki, A., Akazawa, N., Yoshikawa, T., Myoenzono, K., Tagawa, K., \& Maeda, S. (2018). Age-related declines in executive function and cerebral oxygenation hemodynamics. The Tohoku journal of experimental medicine, 245(4), 245-250. doi: $10.1620 /$ tjem.245.245

Hartley, A. A., \& Kieley, J. M. (1995). Adult age differences in the inhibition of return of visual attention. Psychology and Aging, 10(4), 670. doi: 10.1037//08827974.10.4.670

Hartley, A. A., Kieley, J. M., \& Slabach, E. H. (1990). Age differences and similarities in the effects of cues and prompts. Journal of Experimental Psychology: Human Perception and Performance, 16, 523-537. doi: 10.1037//0096-1523.16.3.523

Helton, W. S., \& Warm, J. S. (2008). Signal salience and the mindlessness theory of vigilance. Acta psychologica, 129(1), 18-25. doi: 10.1016/j.actpsy.2008.04.002

Huey, E. D., Goveia, E. N., Paviol, S., Pardini, M., Krueger, F., Zamboni, G., ... \& 
Grafman, J. (2010). Executive dysfunction in frontotemporal dementia and corticobasal syndrome: Erratum. Neurology, 75, 1485. doi: http://dx.doi.org/10.1212/WNL.0b013e3181f98108

Jorm, A. F., Anstey, K. J., Christensen, H., \& Rodgers, B. (2004). Gender differences in cognitive abilities: The mediating role of health state and health habits. Intelligence, 32(1), 7-23. . doi: 10.1016/j.intell.2003.08.001

Jurado, M. B., \& Rosselli, M. (2007). The Elusive Nature of Executive Functions: A Review of our Current Understanding. Neuropsychology Review, 17(3), 213-233. doi: $10.1007 / \mathrm{s} 11065-007-9040-\mathrm{z}$

Kingdon, D., Cardoso, C., \& McGrath, J. J. (2016). Research Review: Executive function deficits in fetal alcohol spectrum disorders and attention-deficit/hyperactivity disorder - a meta-analysis. Journal of Child Psychology and Psychiatry and Allied Disciplines, 57(2), 116-131. doi: 10.1111/jcpp.12451

Kroenke, K., Spitzer, R. L., \& Williams, J. B. (2001). The PHQ-9. Journal of General Internal Medicine, 16(9), 606-613.

Kutner, M. H., Nachtsheim, C. J., Neter, J., \& Li, W. (2005). Applied linear statistical models (5th ed.). New York: McGraw Hill.

Lawrence, A. D., Sahakian, B. J., Hodges, J. R., Rosser, A. E., Lange, K. W., \& Robbins, T. W. (1996). Executive and mnemonic functions in ealry Huntington's disease. Brain, 119, 1633-1645. doi: 10.1093/brain/119.5.1633

Lezak, M. D. (2012). Neuropsychological assessment (5th ed.). New York: Oxford University Press.

Lineweaver, T. T., Bondi, M. W., Thomas, R. G., \& Salmon, D. P. (1999). A Normative Study of Nelson's (1976) Modified Version of the Wisconsin Card Sorting Test in Healthy Older Adults. The Clinical Neuropsychologist, 13(3), 328-347. doi: 
10.1076/clin.13.3.328.1745

Mahoney, F.I., \& Barthel, D. (1965). Functional evaluation: the Barthel Index. Maryland State Medical Journal, 14, 56-61.

Mahoney, J. R., Verghese, J., Goldin, Y., Lipton, R., \& Holtzer, R. (2010). Alerting, orienting, and executive attention in older adults. Journal of the International Neuropsychological Society, 16(5), 877-889. doi: 10.1017/S1355617710000767

Mani, T. M., Bedwell, J. S., \& Miller, L. S. (2005). Age-related decrements in performance on a brief continuous performance test. Archives of clinical neuropsychology, 20(5), 575-586. doi: 10.1016/j.acn.2004.12.008

Manly, T., Heutink, J., Davison, B., Gaynord, B., Greenfield, E., Parr, A., ... \& Robertson, I. H. (2004). An electronic knot in the handkerchief: "Content free cueing" and the maintenance of attentive control. Neuropsychological Rehabilitation, 14(1-2), 89116. doi: https://doi.org/10.1080/09602010343000110

Manly, T., Robertson, I. H., Galloway, M., \& Hawkins, K. (1999). The absent mind: further investigations of sustained attention to response. Neuropsychologia, 37(6), 661-670. doi: 10.1016/s0028-3932(98)00127-4

McDonald, B. C., Flashman, L. A., \& Saykin, A. J. (2002). Executive dysfunction following traumatic brain injury: neural substrates and treatment strategies. NeuroRehabilitation, 17(4), 333-344. doi: 10.3233/NRE-2002-17407

Mitrushina, M. N. (2005). Handbook of normative data for neuropsychological assessment. Oxford University Press.

Mitrushina, M., Boone, K. B., Razani, J., \& D'Elia, L. F. (2005). Handbook of normative data for neuropsychological assessment. Oxford University Press.

Nelson, H. E. (1976). A Modified Card Sorting Test Sensitive to Frontal Lobe Defects. Cortex, 12(4), 313-324. doi: 10.1016/S0010-9452(76)80035-4 
O’Connell, R. G., Bellgrove, M. A., Dockree, P. M., Lau, A., Fitzgerald, M., \& Robertson, I. H. (2008). Self-alert training: Volitional modulation of autonomic arousal improves sustained attention. Neuropsychologia, 46(5), 1379-1390. doi: 10.1016/j.neuropsychologia.2007.12.018

Olgiati, E., Russell, C., Soto, D., \& Malhotra, P. (2016). Motivation and attention following hemispheric stroke. In Progress in brain research (Vol. 229, pp. 343366). Elsevier.

Papagno, C., \& Trojano, L. (2018). Cognitive and behavioral disorders in Parkinson's disease: an update. I: cognitive impairments. Neurological Sciences, 39(2), 215223. doi: $10.1007 / \mathrm{s} 10072-017-3154-8$

Parasuraman, R., Nestor, P. G., \& Greenwood, P. (1989). Sustained-attention capacity in young and older adults. Psychology and aging, 4(3), 339. doi: 10.1037//08827974.4.3.339

Peinemann, A., Schuller, S., Pohl, C., Jahn, T., Weindl, A., \& Kassubek, J. (2005). Executive dysfunction in early stages of Huntington' $\mathrm{s}$ disease is associated with striatal and insular atrophy : A neuropsychological and voxel-based morphometric study. Elsevier, 239, 11-19. doi: 10.1016/j.jns.2005.07.007

Peña-Casanova, J., Blesa, R., Aguilar, M., Gramunt-Fombuena, N., Gómez-Ansón, B., Oliva, R., ... \& Martínez-Parra, C. (2009). Spanish multicenter normative studies (NEURONORMA project): Methods and sample characteristics. Archives of Clinical Neuropsychology, 24(4), 307-319. doi: 10.1093/arclin/acp027

Peña-Casanova, J., Casals-Coll, M., Quintana, M., Sánchez-Benavides, G., Rognoni, T., Calvo, L., ... \& Manero, R. M. (2012). Estudios normativos españoles en población adulta joven (Proyecto NEURONORMA jóvenes): métodos y características de la muestra. Neurología, 27(5), 253-260. doi: https://doi.org/10.1016/j.nrl.2011.12.019 
Petersen, S. E., \& Posner, M. I. (2012). The Attention System of the Human Brain: 20 Years After. Annual Review of Neuroscience, 35, 73-89. . doi: 10.1146/annurevneuro-062111-150525

Pohjasvaara, T., Leskelä, M., Vataja, R., Kalska, H., Ylikoski, R., Hietanen, M., ... \& Erkinjuntti, T. (2002). Post-stroke depression, executive dysfunction and functional outcome. European Journal of Neurology, 9(3), 269-275. doi: 10.1046/j.1468-1331.2002.00396.x

R Development Core Team (2013). R: A language and environment for statistical computing. Vienna, Austria: R Foundation for Statistical Computing. Retrieved from http://www.R-project.org/

Ramos-Galarza, C. (2017). El Resurgir de la Neurociencia Ecuatoriana. Revista Ecuatoriana de Neurología, 26(3), 187-190.

Raz, N., \& Rodrigue, K. M. (2006). Differential aging of the brain: patterns, cognitive correlates and modifiers. Neuroscience \& Biobehavioral Reviews, 30(6), 730-748. doi: 10.1016/j.neubiorev.2006.07.001

Raz, N., Gunning, F. M., Head, D., Dupuis, J. H., McQuain, J., Briggs, S. D., ... \& Acker, J. D. (1997). Selective aging of the human cerebral cortex observed in vivo: differential vulnerability of the prefrontal gray matter. Cerebral cortex (New York, NY: 1991), 7(3), 268-282. doi: 10.1093/cercor/7.3.268

Reitan, R. M. (1958). The validity of the Trail Making Test as an indicator of organic brain damage. Perceptual and Motor Skills, 8, 271-276.

Richardson, E. D., \& Marottoli, R. A. (1996). Education-Specific normative data on common neuropsy-chological indices for individuals older than 75 Years. The Clinical Neuropsychologist, 10(4), 375-381. doi: 10.1080/13854049608406698

Rivera, D., \& Arango-Lasprilla, J. C. (2017). Methodology for the development of 
normative data for Spanish-speaking pediatric populations. NeuroRehabilitation, 41(3), 581-592. doi: 10.3233/NRE-172275

Rivera, D., Olabarrieta-Landa, L., Van der Elst, W., Gonzalez, I., Rodríguez-Agudelo, Y., Aguayo Arelis, A., ... \& Arango-Lasprilla, J. C. (2019). Normative data for verbal fluency in healthy Latin American adults: Letter M, and fruits and occupations categories. Neuropsychology, 33(3), 287. doi: 10.1037/neu0000518

Rivera, D., Perrin, P. B., Stevens, L. F., Garza, M. T., Weil, C., Saracho, C. P., ... \& Arango-Lasprilla, J. C. (2015a). Brief Test of Attention: Normative data for the Latin American Spanish speaking adult population. NeuroRehabilitation, 37(4), 663-676. doi: 10.3233/NRE-151283

Rivera, D., Perrin, P. B., Stevens, L. F., Garza, M. T., Weil, C., Saracho, C. P., ... \& Arango-Lasprilla, J. C. (2015b). Stroop Color-Word Interference Test: Normative data for the Latin American Spanish speaking adult population. NeuroRehabilitation, 37(4), 591-624. doi: 10.3233/NRE-151281

Robertson, I. H., Manly, T., Andrade, J., Baddeley, B. T., \& Yiend, J. (1997). Oops!': performance correlates of everyday attentional failures in traumatic brain injured and normal subjects. Neuropsychologia, 35(6), 747-758. doi: 10.1016/s00283932(97)00015-8

Schretlen, D. J. (1997). Brief test of attention professional manual. Odessa, FL: Psychological Assesment Resources.

Schretlen, D. J. (2010). M-WCST (Modified Wisconsin Card Sorting Test. Odessa, FL: Psychological Assessment Resources.

Schretlen, D., Bobholz, J. H., \& Brandt, J. (1996). Development and psychometric properties of the Brief Test of Attention. The Clinical Neuropsychologist, 10(1), 80-89. doi: https://doi.org/10.1080/13854049608406666 
Shah, S. A., Goldin, Y., Conte, M. M., Goldfine, A. M., Mohamadpour, M., Fidali, B. C., ... \& Schiff, N. D. (2017). Executive attention deficits after traumatic brain injury reflect impaired recruitment of resources. NeuroImage: Clinical, 14, 233-241. doi: 10.1016/j.nicl.2017.01.010

Shallice, T., Burgess, P., \& Robertson, I. (1996). The Domain of Supervisory Processes and Temporal Organization of Behaviour [and Discussion]. Philosophical Transactions of the Royal Society B: Biological Sciences, 351(1346), 1405-1412. doi: $10.1098 /$ rstb.1996.0124

Smith, A. (1982). Symbol Digits Modalities Test. Los Angeles: Western Psychological Services.

Smith, A. (2002). SDMT: test de símbolos y dígitos: Manual. TEA Ediciones.

Sohlberg, M. M., \& Mateer, C. A. (2002). Cognitive Rehabilitation. An Integrative Neuropsychological Approach. In Mycological Research (Vol. 106). Retrieved from papers2://publication/uuid/542C35F2-3BA9-4821-9508-1E3E60550FAD

Sorond, F. A., Schnyer, D. M., Serrador, J. M., Milberg, W. P., \& Lipsitz, L. A. (2008). Cerebral blood flow regulation during cognitive tasks: effects of healthy aging. Cortex, 44(2), 179-184. doi: 10.1016/j.cortex.2006.01.003

Strauss, E., Sherman, E. M. S., \& Spreen, O. (2006). A compendium of neuropsychological tests: Administration, norms, and commentary (3rd Editio). New York, NY: Oxford University Press.

Stroop, J. R. (1935). Studies of interference in serial verbal reactions. Journal of Experimental Psychology, 18(6), 643-662. doi: 10.1037/h0054651

Stuss, D. T. (2011). Functions of the frontal lobes: Relation to executive functions. Journal of the International Neuropsychological Society, 17(5), 759-765. doi: $10.1017 / \mathrm{S} 1355617711000695$ 
Suchy, Y., Ziemnik, R. E., \& Niermeyer, M. A. (2017). Assessment of Executive Functions in Clinical Settings. In Executive Functions in Health and Disease (pp. 551-569). doi: 10.1016/B978-0-12-803676-1.00022-2

Swanberg, M. M., Tractenberg, R. E., Mohs, R., Thal, L. J., \& Cummings, J. L. (2004). Executive dysfunction in Alzheimer disease. Archives of Neurology, 61(4), 556560. doi: 10.1001/archneur.61.4.556 $\ln 61 / 4 / 556$ [pii]

Tales, A., Muir, J. L., Bayer, A., Jones, R., \& Snowden, R. J. (2002). Phasic visual alertness in Alzheimer's disease and ageing. Neuroreport, 13(18), 2557-2560. doi: $10.1097 / 00001756-200212200-00035$

Tramontana, M. G., Cowan, R. L., Zald, D., Prokop, J. W., \& Guillamondegui, O. (2014). Traumatic brain injury-related attention deficits: Treatment outcomes with lisdexamfetamine dimesylate (Vyvanse). Brain Injury, 28(11), 1461-1472. doi: $10.3109 / 02699052.2014 .930179$

Uchiyama, C. L., Mitrushina, M. N., D’Elia, L. F., Satz, P., \& Mathews, A. (1994). Frontal lobe functioning in geriatric and non-geriatric samples: An argument for multimodal analyses. Archives of Clinical Neuropsychology, 9(3), 215-227. doi: $10.1016 / 0887-6177(94) 90027-2$

Van Breukelen, G. J., \& Vlaeyen, J. W. (2005). Norming clinical questionnaires with multiple regression: the Pain Cognition List. Psychological assessment, 17(3), 336. doi: $10.1037 / 1040-3590.17 .3 .336$

Van Der Elst, W., Van Boxtel, M. P., Van Breukelen, G. J., \& Jolles, J. (2006a). Normative data for the Animal, Profession and Letter M Naming verbal fluency tests for Dutch speaking participants and the effects of age, education, and sex. Journal of the International Neuropsychological Society, 12(01), 80-89. doi: $10.1017 / \mathrm{S} 1355617706060115$ 
Van der Elst, W., Van Boxtel, M. P., Van Breukelen, G. J., \& Jolles, J. (2006b). The Letter Digit Substitution Test: normative data for 1,858 healthy participants aged 24-81 from the Maastricht Aging Study (MAAS): influence of age, education, and sex. Journal of Clinical and Experimental Neuropsychology, 28(6), 998-1009. doi: $10.1080 / 13803390591004428$

Vataja, R., Pohjasvaara, T., Mantyla, R., Ylikoski, R., Leppavuori, A., Leskela, M., .. \& Erkinjuntti, T. (2003). MRI correlates of executive dysfunction in patients with ischaemic stroke. European Journal of Neurology, 10(6), 625-631. doi: 10.1046/j.1468-1331.2003.00676.x

Villaseñor-Cabrera, T., Guàrdia-Olmos, J., Jiménez-Maldonado, M., Rizo-Curiel, G., \& Peró-Cebollero, M. (2010). Sensitivity and specificity of the Mini-Mental State Examination in the Mexican population. Quality \& Quantity, 44(6), 1105-1112. doi: https://doi.org/10.1007/s11135-009-9263-6

Welch, M. C. (2001). The prefrontal cortex and the development of executive function in childhood. Handbook of brain and behavior in human development, 767-790.

Zeef, E. J., Sonke, C. J., Kok, A., Buiten, M. M., \& Kenemans, J. L. (1996). Perceptual factors affecting agerelated differences in focused attention: performance and psychophysiological analyses. Psychophysiology, 33(5), 555-565. doi:

10.1111/j.1469-8986.1996.tb02432.x

Zelazo, P., Carter, A., Reznick, J. S., \& Frye, D. (1997). Early Development of Executive Function. Review of General Psychology, 1(2), 198-226. doi: http://doi.apa.org/journals/gpr/1/2/198.html

Zgaljardic, D., Borod, J., Foldi, N., Mattis, P., Gordon, M., Feigin, A., \& Eidelberg, D. (2006). An examination of executive dysfunction associated with frontostriatal circuitry in Parkinson's disease. Journal of Clinical and Experimental 
Neuropsychology, 28(7), 1127-1144. doi: 10.1080/13803390500246910 
Table 1. Demographic characteristics of the sample.

Table 2. Correlations between all scores and demographic variables.

Table 3. Standard deviation (residual) for final multiple linear regression models.

Table 4. Final multiple linear regression models for M-WCST.

Table 5. Final multiple linear regression models for Stroop test.

Table 6. Final multiple linear regression models for TMT.

Table 7. Final multiple linear regression models for SDMT.

Table 8. Final multiple linear regression models for BTA.

Figure 1. Predicted scores for M-WCST Perseverative errors.

Figure 2. Predicted scores for SDMT. 
Table 1.

Demographic characteristics of the sample.

\begin{tabular}{|c|c|c|c|c|c|c|c|}
\hline \multirow{3}{*}{ Age group } & \multirow{3}{*}{$N$} & \multicolumn{2}{|c|}{ Age } & \multicolumn{2}{|c|}{ Education } & \multicolumn{2}{|c|}{ Sex } \\
\hline & & \multirow{2}{*}{ Mean } & \multirow{2}{*}{ SD } & \multirow{2}{*}{ Mean } & \multirow{2}{*}{ SD } & Woman & Man \\
\hline & & & & & & $n$ & $n$ \\
\hline $20 \pm 2$ year & 41 & 20.1 & 1.4 & 12.7 & 3.1 & 22 & 19 \\
\hline $25 \pm 2$ year & 62 & 24.9 & 1.4 & 13.6 & 3.7 & 26 & 36 \\
\hline $30 \pm 2$ year & 30 & 29.8 & 1.5 & 15.0 & 4.4 & 19 & 11 \\
\hline $35 \pm 2$ year & 11 & 35.0 & 1.4 & 14.1 & 5.2 & 17 & 13 \\
\hline $40 \pm 2$ year & 26 & 39.9 & 1.4 & 12.2 & 4.1 & 14 & 12 \\
\hline $45 \pm 2$ year & 26 & 44.6 & 1.1 & 13.3 & 4.2 & 14 & 12 \\
\hline $50 \pm 2$ year & 20 & 50.1 & 1.6 & 13.2 & 4.7 & 14 & 6 \\
\hline $55 \pm 2$ year & 20 & 55.7 & 1.4 & 14.1 & 6.2 & 13 & 7 \\
\hline $60 \pm 2$ year & 16 & 60.3 & 1.2 & 14.5 & 4.6 & 9 & 7 \\
\hline $65 \pm 2$ year & 13 & 64.5 & 1.5 & 13.4 & 6.0 & 7 & 6 \\
\hline $70 \pm 2$ year & 11 & 68.5 & 0.7 & 11.8 & 5.0 & 6 & 5 \\
\hline $75 \pm 2$ year & 11 & 75.2 & 1.4 & 11.5 & 6.8 & 5 & 6 \\
\hline$>78$ year & 16 & 81.2 & 1.9 & 9.6 & 3.7 & 8 & 8 \\
\hline Total & 322 & 41.3 & 18.2 & 13.2 & 4.6 & 174 & 148 \\
\hline
\end{tabular}

Note. $\mathrm{SD}=$ Standard deviation 
Table 2.

Correlations between all scores and demographic variables.

\begin{tabular}{cccc}
\hline Score & Age & Education & $\dagger$ Sex \\
\hline M-WCST Categories & $-.424^{* *}$ & $.371^{* *}$ & .061 \\
\hline $\begin{array}{c}\text { M-WCST } \\
\text { Perseverative errors }\end{array}$ & $.512^{* *}$ & $-.216^{* *}$ & -.087 \\
\hline M-WCST Total errors & $.432^{* *}$ & $-.262^{* *}$ & -.088 \\
\hline Stroop Word & $-.412^{* *}$ & $.382^{* *}$ & $.127^{*}$ \\
\hline Stroop Color & $-.467^{* *}$ & $.339^{* *}$ & $.118^{*}$ \\
\hline Stroop Word-color & $-.527^{* *}$ & $.390^{* *}$ & .099 \\
\hline Stroop Interference & $-.268^{* *}$ & $.171^{* *}$ & .014 \\
\hline TMT-A & $.457^{* *}$ & $-.333^{* *}$ & $-.137^{*}$ \\
\hline TMT-B & $.542^{* *}$ & $-.402^{* *}$ & -.090 \\
\hline SDMT & $-.581^{* *}$ & $.526^{* *}$ & .054 \\
\hline BTA & $-.212^{* *}$ & $.358^{* *}$ & .037
\end{tabular}

Note. $\dagger=$ Reference group women $=0 ; * *=p<0.001 ; *=p<0.05$ 
Table 3.

Standard deviation (residual) for final multiple linear regression models.

\begin{tabular}{|c|c|c|}
\hline Score & Predicted value $\left(\widehat{Y}_{i}\right)$ & $S D_{e}$ (residual) \\
\hline \multirow{4}{*}{ M-WCST Categories } & $\leq 3.648$ & 1.767 \\
\hline & $3.649-4.383$ & 1.779 \\
\hline & $4.384-5.012$ & 1.459 \\
\hline & $\geq 5.013$ & 1.086 \\
\hline \multirow{4}{*}{ M-WCST Perseverative errors } & $\leq 3.247$ & 2.981 \\
\hline & $3.248-5.188$ & 4.229 \\
\hline & $5.189-7.790$ & 5.845 \\
\hline & $\geq 7.791$ & 10.384 \\
\hline \multirow{4}{*}{ M-WCST Total errors } & $\leq 9.203$ & 6.604 \\
\hline & 9.204-13.243 & 8.582 \\
\hline & $13.244-16.629$ & 9.842 \\
\hline & $\geq 16.630$ & 10.551 \\
\hline Stroop Word & All values & 17.063 \\
\hline Stroop Color & All values & 14.441 \\
\hline Stroop Word-Color & All values & 10.090 \\
\hline Stroop Interference & All values & 9.230 \\
\hline \multirow{4}{*}{ TMT-A } & $\leq 41.662$ & 17.694 \\
\hline & $41.663-49.254$ & 20.348 \\
\hline & $49.255-58.507$ & 17.390 \\
\hline & $\geq 58.508$ & 21.971 \\
\hline \multirow{4}{*}{ TMT-B } & $\leq 79.147$ & 30.935 \\
\hline & $79.148-101.535$ & 42.072 \\
\hline & $101.536-131.200$ & 59.061 \\
\hline & $\geq 131.201$ & 75.240 \\
\hline SDMT & All values & 9.777 \\
\hline \multirow{4}{*}{ BTA } & $\leq 15.159$ & 3.544 \\
\hline & $15.160-15.954$ & 3.078 \\
\hline & $15.955-16.833$ & 2.656 \\
\hline & $\geq 16.834$ & 2.262 \\
\hline
\end{tabular}


Table 4.

Final multiple linear regression models for M-WCST.

\begin{tabular}{|c|c|c|c|c|c|c|c|}
\hline Score & Variable & B & $\begin{array}{c}\text { Std. } \\
\text { Error }\end{array}$ & Stand. B & $t$ & Sig. & $\begin{array}{c}\text { Adjusted } \\
\mathbf{R}^{\mathbf{2}} \\
\end{array}$ \\
\hline \multirow{3}{*}{$\begin{array}{l}\text { M-WCST } \\
\text { Categories }\end{array}$} & (Constant) & 4.229 & .087 & & 48.791 & $<.001$ & \multirow{3}{*}{.278} \\
\hline & Age & -.039 & .005 & -.384 & -8.022 & $<.001$ & \\
\hline & Education & .129 & .019 & .322 & 6.732 & $<.001$ & \\
\hline \multirow{7}{*}{$\begin{array}{c}\text { M-WCST } \\
\text { Perseverative } \\
\text { errors }\end{array}$} & (Constant) & 5.366 & .732 & & 7.333 & $<.001$ & \multirow{7}{*}{.367} \\
\hline & Age & .148 & .025 & .329 & 5.844 & $<.001$ & \\
\hline & $\mathrm{Age}^{2}$ & .004 & .001 & .175 & 2.502 & .013 & \\
\hline & Education & -.251 & .084 & -.140 & -2.979 & .003 & \\
\hline & Education $^{2}$ & -.050 & .023 & -.145 & -2.204 & .028 & \\
\hline & Age $\mathrm{x}$ Edu & .016 & .005 & .169 & 3.432 & .001 & \\
\hline & $\begin{array}{c}\mathrm{Age}^{2} \mathrm{x} \\
\mathrm{Edu}^{2}\end{array}$ & .000 & .000 & .291 & 3.493 & .001 & \\
\hline \multirow{5}{*}{$\begin{array}{l}\text { M-WCST } \\
\text { Total errors }\end{array}$} & (Constant) & 12.087 & .735 & & 16.454 & $<.001$ & \multirow{5}{*}{.272} \\
\hline & Age & .199 & .034 & .341 & 5.842 & $<.001$ & \\
\hline & $\mathrm{Age}^{2}$ & .005 & .002 & .182 & 3.031 & .003 & \\
\hline & Education & -.574 & .116 & -.247 & -4.929 & $<.001$ & \\
\hline & Age $\times$ Edu & .026 & .006 & .216 & 4.163 & $<.001$ & \\
\hline
\end{tabular}

Note. M-WCST $=$ Modified-Wisconsin Card Sorting Test 
Table 5.

Final multiple linear regression models for Stroop test.

\begin{tabular}{|c|c|c|c|c|c|c|c|}
\hline Score & Variable & B & $\begin{array}{c}\text { Std. } \\
\text { Error }\end{array}$ & Stand. B & $\mathbf{t}$ & Sig. & $\begin{array}{c}\text { Adjuste } \\
\mathrm{d} \mathrm{R}^{2}\end{array}$ \\
\hline \multirow{3}{*}{ Stroop Word } & (Constant) & 93.132 & .954 & & 97.638 & $<.001$ & \multirow{3}{*}{.276} \\
\hline & Age & -.409 & .053 & -.369 & -7.713 & $<.001$ & \\
\hline & Education & 1.473 & .210 & .335 & 7.001 & $<.001$ & \\
\hline \multirow{3}{*}{ Stroop Color } & (Constant) & 65.477 & .807 & & 81.109 & $<.001$ & \multirow{3}{*}{.293} \\
\hline & Age & -.409 & .045 & -.431 & -9.111 & $<.001$ & \\
\hline & Education & 1.068 & .178 & .284 & 5.999 & $<.001$ & \\
\hline \multirow{3}{*}{$\begin{array}{c}\text { Stroop } \\
\text { Word-Color }\end{array}$} & (Constant) & 37.555 & .564 & & 66.583 & $<.001$ & \multirow{3}{*}{.380} \\
\hline & Age & -.343 & .031 & -.485 & -10.942 & $<.001$ & \\
\hline & Education & .922 & .124 & .329 & 7.413 & $<.001$ & \\
\hline \multirow{2}{*}{$\begin{array}{c}\text { Stroop } \\
\text { Interference }\end{array}$} & (Constant) & -.389 & .515 & & -.755 & .451 & \multirow{2}{*}{.069} \\
\hline & Age & -.142 & .028 & -.268 & -4.985 & $<.001$ & \\
\hline
\end{tabular}


Table 6.

Final multiple linear regression models for TMT.

\begin{tabular}{|c|c|c|c|c|c|c|c|}
\hline Score & Variable & B & $\begin{array}{c}\text { Std. } \\
\text { Error }\end{array}$ & Stand. B & $\mathbf{t}$ & Sig. & $\begin{array}{c}\text { Adjusted } \\
\mathbf{R}^{\mathbf{2}} \\
\end{array}$ \\
\hline \multirow{3}{*}{ TMT-A } & (Constant) & 51.670 & 1.092 & & 47.322 & $<.001$ & \multirow{3}{*}{.281} \\
\hline & Age & .536 & .061 & .421 & 8.824 & $<.001$ & \\
\hline & Education & -1.411 & .241 & -.280 & -5.861 & $<.001$ & \\
\hline \multirow{4}{*}{ TMT-B } & (Constant) & 101.365 & 4.426 & & 22.903 & $<.001$ & \multirow{4}{*}{.428} \\
\hline & Age & 1.540 & .206 & .387 & 7.491 & $<.001$ & \\
\hline & $\mathrm{Age}^{2}$ & .038 & .010 & .200 & 3.836 & $<.001$ & \\
\hline & Education & -4.967 & .679 & -.315 & -7.313 & $<.001$ & \\
\hline
\end{tabular}

Note. TMT $=$ Trial Making Test 
Table 7.

Final multiple linear regression models for SDMT.

\begin{tabular}{cccccccc}
\hline Score & Variable & B & $\begin{array}{c}\text { Std. } \\
\text { Error }\end{array}$ & Stand. B & $\mathbf{t}$ & Sig. & $\begin{array}{c}\text { Adjusted } \\
\mathbf{R}^{\mathbf{2}}\end{array}$ \\
\hline \multirow{3}{*}{ SDMT } & (Constant) & 42.427 & .547 & & 77.622 & $<.001$ & \\
\cline { 2 - 8 } & Age & -.417 & .030 & -.522 & -13.709 & $<.001$ & .542 \\
\cline { 2 - 8 } & Education & 1.453 & .121 & .459 & 12.056 & $<.001$ & \\
\hline
\end{tabular}

Note. SDMT $=$ Symbol Digit Modalities Test 
Table 8 .

Final multiple linear regression models for BTA.

\begin{tabular}{cccccccc}
\hline Score & Variable & B & $\begin{array}{c}\text { Std. } \\
\text { Error }\end{array}$ & Stand. B & $\mathbf{t}$ & Sig. & $\begin{array}{c}\text { Adjusted } \\
\mathbf{R}^{\mathbf{2}}\end{array}$ \\
\hline \multirow{3}{*}{ BTA } & (Constant) & 16.499 & .216 & & 76.355 & $<.001$ & \\
\cline { 2 - 8 } & Age $^{2}$ & -.002 & .000 & -.254 & -4.949 & $<.001$ & .185 \\
\cline { 2 - 8 } & Education & .219 & .036 & .309 & 6.021 & $<.001$ & \\
\hline
\end{tabular}

Note. $\mathrm{BTA}=$ Brief Test of Attention 


\section{Perseverative Errors}

30

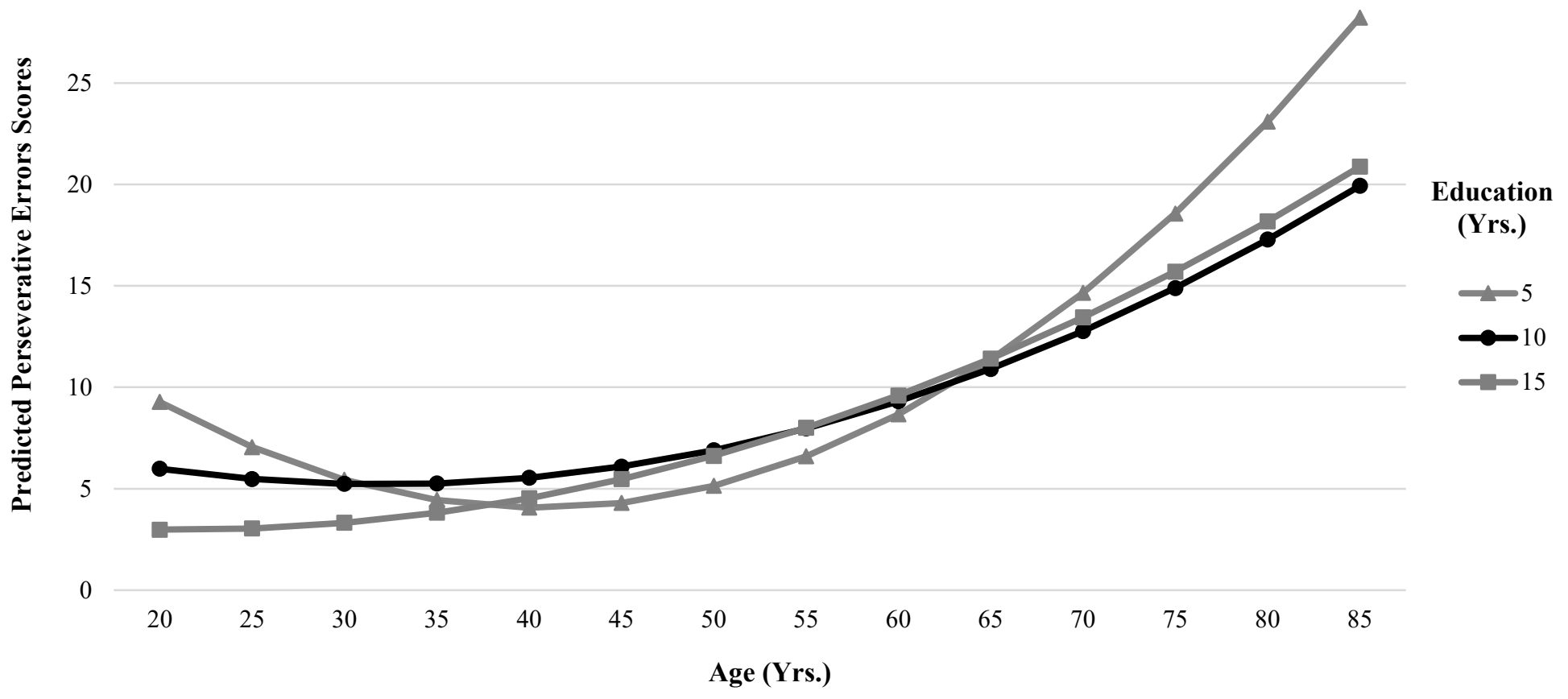

Figure 1. Predicted mean Perseverative Errors scores as a function of age and education from the Ecuadorian sample. 


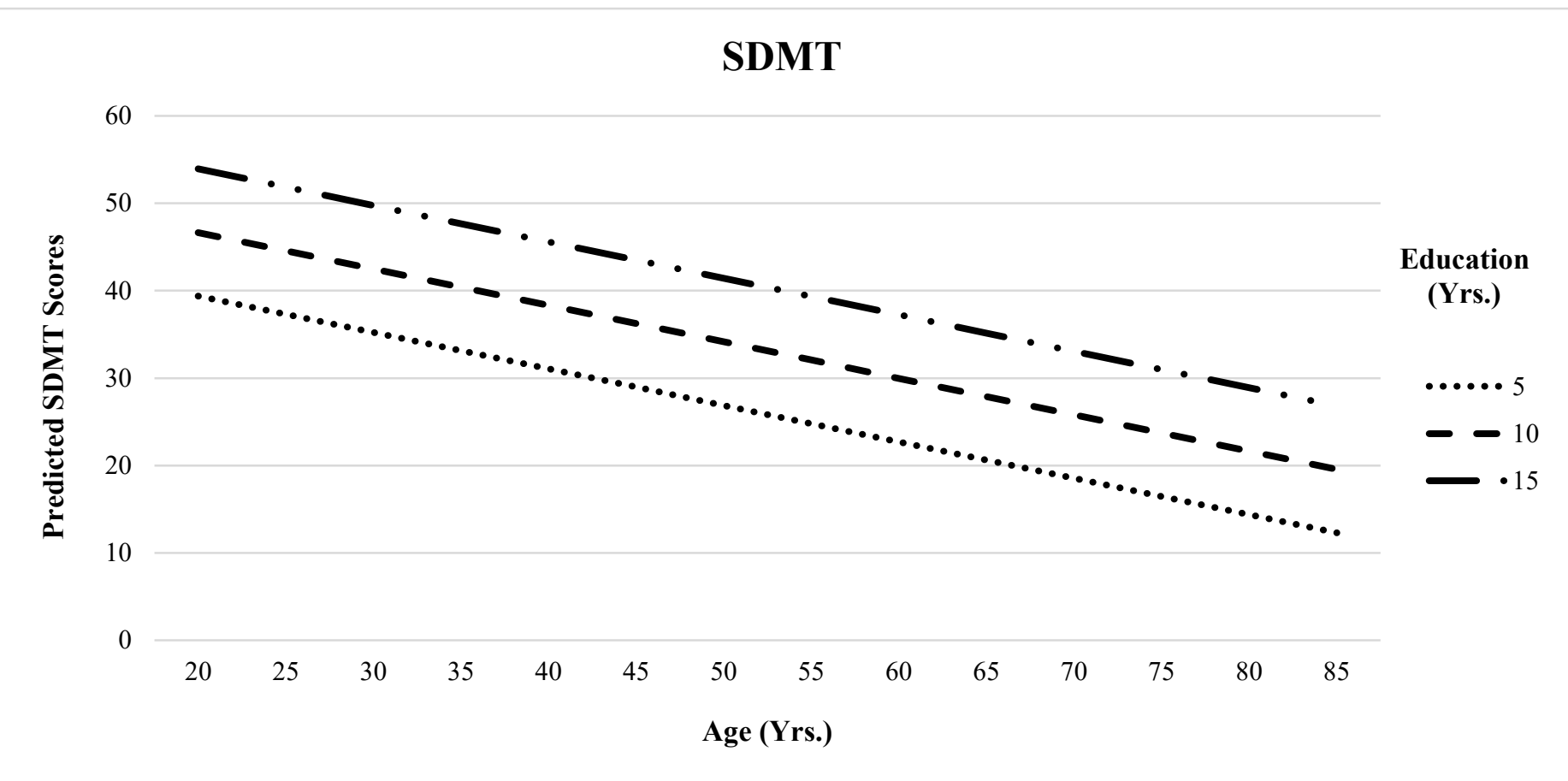

Figure 2. Predicted mean SDMT scores as a function of age and education from the Ecuadorian sample. 